\title{
Narrativas policiais sobre prevenção da violência e juventudes: experiências no Brasil e na Escócia
}

\author{
Police reports on the prevention of violence among youths: \\ experiences in Brazil and Scotland
}

Juliana Silva Corrêa (https://orcid.org/0000-0002-7163-6597) ${ }^{1}$

Fátima Regina Cecchetto (https://orcid.org/0000-0003-3080-5582) ${ }^{2}$

Fernando Lannes Fernandes (https://orcid.org/0000-0002-4377-4597) ${ }^{3}$

${ }^{1}$ Escola Nacional de Saúde Pública Sérgio Arouca, Fundação Oswaldo Cruz (Fiocruz). R. Leopoldo Bulhões 1480, Manguinhos. 21041-210 Rio de Janeiro RJ Brasil. correajugeo@gmail.com ${ }^{2}$ Laboratório de Educação em Ambiente e Saúde, Instituto Oswaldo Cruz, Fiocruz. Rio de Janeiro RJ Brasil.

${ }^{3}$ University of Dundee.

Dundee Escócia.

\begin{abstract}
This study analyzes the reports of police officers on violence prevention initiatives in the city of Rio de Janeiro, Brazil, and in the city of Glasgow, Scotland. The theoretical-methodological framework of the social sciences, based on interpretative anthropology, was used to analyze the data. The results reveal the demand for intervention at an increasingly early stage, aiming at young people from outlying urban neighborhoods in both countries. Dysfunctional family environment, social vulnerability and involvement with crime are cited as risk factors. Reports such as these, promote the prospect of negativity and of labeling youth as a "social problem", reuniting formulations that are structured on the basis of the symbiosis between the role of agent of the state and the moral ethos that supports the individual decisions of police officers. The study highlights the complexity of the interventions, and the dispute around the forms of control and the maintenance of order in the two contexts analyzed. It is suggested that future studies investigate how the rationale present in the field of public health has been incorporated into public safety policies and programs. The risks of narratives reinforcing the stigmatization of underprivileged youths in violence prevention initiatives are emphasized.
\end{abstract}

Key words Prevention, Violence, Youth, Public Health, Policing
Resumo Esse estudo analisa as narrativas de policiais sobre iniciativas de prevenção da violência na cidade do Rio de Janeiro, no Brasil e na cidade de Glasgow, na Escócia. Utilizou-se o referencial teórico-metodológico das ciências sociais, com os aportes da antropologia interpretativa. Os resultados apontam para a produção de intervenções cada vez mais precoces dirigidas às juventudes de periferias urbanas nos dois países. Prevalecem narrativas que reforçam ideias do ambiente familiar desestruturado, da vulnerabilidade social e do envolvimento com o crime como fatores de risco. Tais narrativas privilegiam a ótica do negativismo e da juventude como "problema social", unificando formulações que se estruturam a partir da simbiose entre o papel de agente do estado e o ethos moral que sustenta as decisões individuais de policiais. O estudo sinaliza para a complexidade das intervenções, bem como para a disputa em torno dos modos de controle e da produção da ordem nos dois contextos analisados. Sugere-se investigar, em estudos futuros, como a racionalidade presente no campo da saúde pública vem sendo incorporada em políticas e programas de segurança pública. Ressaltam-se os riscos das narrativas que reforçam estigmas sobre os jovens pobres em iniciativas de prevenção da violência.

Palavras-chave Prevenção, Violência, Juventude, Saúde pública, Policiamento 


\section{Introdução}

Globalmente, a violência é um fenômeno que está associado aos homicídios, lesões físicas e incapacidades e tem sérios efeitos na saúde mental dos indivíduos ${ }^{1}$. Seus impactos reduzem a coesão social, diminuem as capacidades produtivas e promovem a estigmatização de grupos sociais, bem como de bairros e regiões. Em função disto, pode-se dizer que violência é um grave problema de saúde pública demandando respostas variadas a nível local, nacional e internacional ${ }^{2}$.

Embora se configure como uma questão de saúde global, iniciativas de prevenção e redução das violências, sobretudo as voltadas para jovens, bem como estudos avaliativos dessas intervenções ainda são escassos e se concentram, principalmente, em países de renda alta ${ }^{1,3}$.

Este artigo busca compreender as percepções de policiais que atuaram em programas de prevenção da violência no Brasil e na Escócia. Nossa análise concentra-se em duas experiências particulares que buscaram de um lado, atuar em um contexto de violência entre gangues juvenis na cidade de Glasgow, onde uma aparente coesão político-institucional viabilizou um conjunto de ações coordenadas que resultaram na redução da violência comunitária e que teve como eixo estruturante a abordagem da saúde pública. De outro, a experiência no Rio de Janeiro, onde as violências são atravessadas por um cenário mais complexo que envolve a presença de grupos criminosos que exercem o domínio armado nos territórios, assim como uma política de segurança pública orientada pela "guerra às drogas", política que tornou ilegal o uso e o tráfico de certas substâncias, mobilizando um aparato repressivo para fazer valer a criminalização ${ }^{4}$ com o uso desmedido da força nas chamadas "operações policiais".

O foco na juventude se justifica pela relevância da construção social de jovens de periferias urbanas como um "problema social". Juventudes cujos territórios e estilos de vida carregam alta carga de estigma e têm sido sistematicamente associadas a lugares perigosos e comportamentos "desviantes" nas narrativas que circundam os debates sobre segurança pública, tanto no Brasil quanto na Escócia. Com efeito a atenção para os "riscos" e "vulnerabilidades" associados a juventude tem sido fatores que mobilizam agendas governamentais dirigidas para essa faixa populacional. Não obstante, temas e conceitos associados a saúde pública se tornam imbricados nos problemas que circundam jovens como os principais "alvos", "beneficiários" e "clientes" de iniciativas que buscam gerir e encontrar soluções para questões como gravidez na adolescência, doenças sexualmente transmissíveis, uso abusivo de drogas e, no caso do presente estudo, a participação em ações criminosas e violentas.

Refletir criticamente sobre como essas iniciativas são formuladas e como impactam nas práticas cotidianas implica em desvelar os sentidos implícitos e explícitos atribuídos às categorias utilizadas pelos agentes de segurança para descrever as condições de interação e as modalidades de policiar seus respectivos públicos juvenis.

Ao tomarmos a noção prevenção da violência como cenário e bastidor foi possível iluminar processos específicos e dinâmicas acionadas em relação aos grupos que são os principais alvos dos programas sociais e políticas penais cuja preocupação primordial, quando menos é “atacar” comportamentos indesejáveis ou incivilidades, quando mais, "aplaudir" a redução da maioridade penal e/ou o extermínio. Importa com esse texto, encorajar modalidades de reflexão sobre políticas que orientam as práticas direcionadas a conter e controlar determinados segmentos da população onde se emprega meios de punição arbitrários e desproporcionais visando a neutralização dos riscos que representam para a sociedade.

\section{Percurso metodológico}

Para realizar este trabalho, optou-se, em primeiro lugar por caracterizar os programas locais que preconizavam ações de prevenção da violência. O primeiro, localizado na cidade do Rio de Janeiro foi o programa das Unidades de Polícia Pacificadora (UPP). O segundo, no contexto escocês, foi o programa Community Initiative to Reduce Violence desenvolvido na cidade de Glasgow (CIRV-Glasgow). Não se trata de um estudo comparativo, mas as iniciativas analisadas trazem contribuições importantes que permitem dialogar com políticas desenvolvidas com foco nas juventudes de um lado e de outro. O ponto de encontro em ambos os cenários é o fato de terem policiais desenvolvendo ações e projetos em áreas pobres alegadamente com o intuito de prevenir a violência e o crime.

O estudo se beneficia de trabalho de campo etnográfico realizado entre os anos de 2016 e 2017 no Brasil e na Escócia, integrando parte de uma pesquisa de doutoramento ${ }^{5}$. Em ambos, percorreu-se os caminhos da observação e das conversas informais entremeadas pelos depoimentos mais circunspectos dos agentes. Foram realizadas 
15 entrevistas-semiestruturadas, sendo sete com policiais em Glasgow, todos do sexo masculino, posicionados em patentes superiores na hierarquia policial escocesa. No Rio de Janeiro foram entrevistados oito policiais militares, sendo cinco homens e três mulheres envolvendo praças e oficiais. Ressalte-se, aqui, a presença mais expressiva de homens policiais entre os entrevistados que, dada a segmentação institucional de gênero, tem a hegemonia nas atividades de policiamento nos dois países ${ }^{6,7}$.

Utilizou-se como referencial teórico-metodológico os aportes da antropologia interpretati$\mathrm{va}^{8,9}$. As contribuições de Geertz ${ }^{8}$ foram de extrema relevância para a análise dos relatos policiais sobre a ideia de prevenção da violência. Com sua proposta de colocar sob descrição densa os sistemas de significados atribuídos pelos interlocutores às suas práticas e representações foi possível apreender, de forma contrastiva, as visões de mundo e moralidades da profissão policial circunscritas pela moldura institucional local, à luz dos fins sociais e políticos de cada contexto.

O projeto que deu origem a este trabalho foi apresentado e aprovado pelo Comitê de Ética e Pesquisa da Escola Nacional de Saúde Pública da Fundação Oswaldo Cruz e pelo Comitê de Ética da Universidade de Dundee.

\section{Resultados}

\section{As Unidades de Polícia Pacificadora no Rio de Janeiro, Brasil}

O Estado do Rio de Janeiro, em meados dos anos 2000 contou com o desenvolvimento de um projeto de Polícia de Proximidade nas favelas. A ideia de "polícia de proximidade" surge nos documentos oficiais alguns anos depois da implantação das UPP ${ }^{10}$. Consistiria em uma modalidade de policiamento inspirada no policiamento comunitário. Essa iniciativa estatal almejava a mudança de padrões de policiamento baseados em operações policiais violentas nessas áreas. Em boa parte dessas operações dezenas de policiais armados com fuzis, a bordo de um veículo blindado, denominado "caveirão", invadem áreas densamente povoadas para prender suspeitos e/ou aprender drogas e armas, mas ao custo de intensos tiroteios, que resultam em mortes e ruptura do cotidiano das localidades. O projeto das UPP ambicionava (re)estabelecer o controle territorial das áreas de favelas, vistas como territórios sob o monopólio de domínios armados que exercem a violência ilegal comunitária ${ }^{10}$. Para atuar nas áreas definidas, foram convocados policiais jovens, recém-ingressados na corporação, concebidos como livres dos "vícios" institucionais, embora isso não fosse a regra. Uma das estratégias adotadas foi a realização de ações de cunho educacional e social pela polícia, como forma de estabelecer novos vínculos com as comunidades locais. Tem-se que em 2017, segundo informações disponibilizadas pela Assessoria de Proximidade das UPP, 147 policiais militares estavam atuando em 127 projetos sociais nas favelas, envolvendo principalmente aulas de reforço escolar, informática, artes marciais e balé.

\section{Policiamento de proximidade, projetos sociais e prevenção}

A orientação institucional, mais ou menos clara, consistia em estabelecer relações de proximidade nas comunidades "resgatadas" ou "pacificadas". Os projetos sociais emergiram como um dispositivo de justificação para se contrapor a experiências pretéritas dos moradores com a polícia marcadas pela desconfiança e suspeição recíprocas, alimentadas pelo medo de sucessivas incursões violentas para o combate ao crime ${ }^{11}$. Tem-se um novo horizonte de atuação que ambiciona reposicionar a atividade policial, cuja pedra de toque seria o desempenho individual do agente nas localidades. A prevenção estaria ligada às ações para ocupar o tempo ocioso de crianças e jovens com atividades culturais e esportivas. As atividades pedagógicas tinham o intuito de promover referências positivas na contramão da "má" influência exercida pelos bandos armados locais. Os policiais serviriam de modelos para que os indivíduos se afastassem de condutas delituosas:

Eu queria colocar um polícia para servir de referência, porque até então a referência que as crianças tinham na comunidade era de traficantes (oficial).

No tempo das UPP observou-se o fortalecimento dos discursos do resgate social, com a reconfiguração desses jovens como indivíduos socialmente vulneráveis que teriam a chance de terapias inclusivas, mediante as oportunidades de "mudar de vida", que nas palavras de um cabo, impediriam que os jovens "entrassem para o tráfico". Os projetos da polícia de proximidade, então, estariam, de alguma maneira, prevenindo a cooptação destes indivíduos.

Para alguns oficiais, entretanto, o impacto nos índices locais de crimes seria discutível. Haveria a 
necessidade de construir evidências sobre os resultados práticos que demonstrassem o impacto do trabalho preventivo. Diversas foram as críticas dirigidas a estas atividades, tanto internas quanto externas. A oferta de projetos sociais para moradores fora vista como uma extensão das competências policiais para além de suas atribuições e em alguns casos até mesmo, um obstáculo para a realização do que era considerado o verdadeiro trabalho policial, isto é, ações de policiamento ostensivo nas localidades.

Para lidar com as críticas, a ideia de que "a polícia não faz projeto social, a polícia faz projeto de prevenção" foi acionada por autoridades no Comando Geral da Polícia Militar como estratégia para justificar o trabalho exercido dentro do escopo do fazer policial. O rótulo "projetos de prevenção" fora uma maneira estratégica encontrada para, de um lado, responder às críticas externas e defender as ações como um trabalho de polícia, e de outro, induzir internamente uma discussão na corporação que fosse na direção de fomentar uma reflexão maior sobre como conduzir projetos "baseados em evidências mensuráveis":

Se você quer prevenir a violência, se você quer evitar o conflito armado, a letalidade, tanto do policial como a letalidade em geral, você precisa de projetos baseados em evidências mensuráveis (oficial).

Os projetos de prevenção foram apresentados como a grande oportunidade aberta para os vulneráveis, uma chance de dar uma expectativa de futuro. A prevenção implicou em mudar o foco de atuação policial, os meios e métodos utilizados, o que não se fez sem conflitos, acirrando as disputas em torno dos seus sentidos:

Na minha visão e de muitos policiais isso é prevenção. A minha aula de música é um aliciamento preventivo. É atividade operacional de prevenção. O policial agindo com reeducação está interligando a educação e a polícia (oficial).

A proposta de substituição das armas de fogo por instrumentos musicais e atividades esportivas (o violão, a bola, o tatame) operou no plano simbólico como uma estratégia de convencimento calcada em uma espécie de soft power. Esta estratégia tem sido usada como um recurso por organizações não governamentais que se baseiam em slogans como "cultura é a nossa arma", visando competir com o apelo do chamado crime-negócio do varejo de drogas e armas. Trocar a arma pelo violão representaria uma transformação de paradigmas de atuação policial, vista como possível em um determinado contexto no qual havia a diminuição dos confrontos armados ${ }^{8}$. Apesar de se apresentar como um contraponto havia uma tensão com a lógica em uso "da guerra contra o inimigo" - elemento discursivo presente nas falas de policiais, sustentada pela política de segurança pública em vigor em vários estados do Brasil.

\section{Aliciando crianças e salvando jovens}

A maior parte dos projetos centrava-se no público infantil. As crianças eram vistas como objeto privilegiado da prevenção, enquanto os mais velhos, o jovem - sempre um sujeito do sexo masculino - era associado às ações de repressão e designado como "o grande problema". A convivência prolongada com os grupos armados locais era entendida um fator que dificultava tanto a aproximação com os policiais quanto a suposta prevenção, como já dito. A ideia de uma "geração perdida" (para o "tráfico") circulava como uma espécie de mantra, revelando preconceitos construídos sobre as juventudes de favela ao longo das últimas décadas ${ }^{12}$. Não à toa, um dos projetos desenvolvidos nas UPP ganhou grande visibilidade por promover artes marciais, se chamava "Geração UPP”. Numa perspectiva pragmática, a luta seria um instrumento essencial para agir contra os inúmeros fatores de risco que atravessam a vida dessas crianças, seja pelo ambiente familiar ou o meio social que se vive, cercado pela escassez e pela precariedade. Nas entrelinhas, subentendese a demarcação de fronteiras entre uma "geração anterior", irrecuperável e uma geração que ainda tem o que ser feito. Tem-se aqui a ilusão etiológica de que o mal se corta pela raiz $^{13}$.

A busca por canais de reciprocidade e colaboração com os sujeitos policiados deveriam responder às oportunidades ofertadas para a formação do "cidadão de bem". O uso dessa classificação, nativa, construída em oposição a bandidos ou marginais, revela o anseio de que a instituição do policial de projeto social figurasse como modelo de imitação prestigiosa para os jovens, sintetizada na frase "não vai querer se envolver com drogas, não vai querer fazer nada de errado, vai querer ser cidadão de bem (oficial feminino)".

No tempo dos projetos da UPP foram oferecidas tutelas para a conversão a um novo "habitus", através de práticas esportivas e culturais protagonizadas por policiais, passando pela orientação moral. Propunha-se uma espécie de conversão, viabilizada pelas ações pedagógicas para desenvolver parcela da juventude ainda não totalmente "perdida para o tráfico". Sob a égide da gramática da prevenção da violência, as ações policiais 
não estritamente combativas seriam como um referencial da instauração de um novo universo: da polícia como um mediador civilizatório, um meio de salvação para a juventude pobre, através da inclusão social. As terapias coercitivas dariam lugar as abordagens inclusivas, mediante o investimento em práticas reeducadoras, que pudessem “disputar os jovens com o tráfico". Seu atrativo seria fornecer espaços de aprendizado civilizatório, tendo o policial como modelo correcional a ser seguido.

O reconhecimento da necessidade de criar alternativas às incursões violentas apontava para uma mudança valorativa que se fez acompanhar da ênfase em uma polícia de proximidade em contraste com uma polícia de operações, padrão contestado, embora hegemônico na política de segurança do Estado do Rio de Janeiro. A narrativa da prevenção foi usada como uma forma de desenvolver ações e programas como rotas alternativas, abrindo brechas na trajetória de muitos jovens das periferias que acabam mortos ou presos.

O programa das UPP tornou-se uma referência como um novo modelo de segurança pública no Estado, expresso pela redução pontual de tiroteios e incursões em algumas favelas. Embora não tenha atingido todos os objetivos preconizados, operou no plano concreto e simbólico para a mudança temporária na atuação policial. No entanto, alterações substantivas na orientação política do programa contribuíram para a descaracterização de suas diretrizes, levando a questionamentos sobre as bases operacionais, ideológicas e políticas em torno da forma como o Estado brasileiro administra a ordem e os conflitos sociais. Um dos desafios da UPP foi viabilizar a mudança de práticas violentas e arbitrárias do Estado nas periferias pobres, como já mencionado, talhadas pelo método do "combate ao inimigo interno", profundamente enraizada nos meios policiais ${ }^{11}$.

\section{O Community Initiative to Reduce Violence (CIRV) em Glasgow, Escócia}

O CIRV Glasgow foi um programa desenvolvido entre os anos de 2008 e 2012 cujo objetivo era reduzir as taxas de crimes entre gangues juvenis, motivadas por rivalidades territoriais que resultavam em agravos e mortes ${ }^{12}$. O programa mesclava a abordagem da saúde pública para a prevenção da violência com a estratégia de dissuasão ${ }^{14}$. Esta última consistia no reforço sistemático da mensagem sobre a intolerância quanto ao que é designado como comportamento antisso- cial, envolvendo desde casos de perturbação da ordem, agressão grave, tentativa de homicídio e homicídio $^{15}$. Aos participantes eram oferecidos serviços sociais diversos em troca da colaboração com o programa, se comprovada a disposição para mudança do comportamento de acordo com as metas preconizadas. Embora coordenado pela polícia, o programa funcionava a partir de uma parceria multisetorial (multi-agency partnership) isto é, um conglomerado de agências estatais e privadas além de vários outros agentes da sociedade civil (ONGs, instituições de caridade, organizações comunitárias).

O CIRV se estruturava em etapas ou fases, classificando os jovens e as gangues conforme seus graus de risco: "baixo, médio e alto". "Sessões de autorreferência" (self-referral) eram meios através dos quais a equipe composta em geral por policiais, assistentes sociais e educadores recomendava que os indivíduos potencial ou concretamente "envolvidos com as gangues" aderissem ao programa. Conforme descrito pelos entrevistados, as sessões, realizadas em cortes distritais, consistiam em comunicar aos jovens as possíveis consequências do comportamento antissocial. Levá-los à presença de um juiz dava o tom de advertência sobre as punições cabíveis como "vir a se sentar no banco dos réus", nos casos de reincidência. Um espaço era reservado para o testemunho de familiares de jovens feridos ou mortos e de indivíduos que já tinham cumprido pena por assassinato. Completando o círculo do processo de dissuasão, policiais uniformizados (Gangs Task Force), permaneciam na sala, com o fito de lembrar o papel repressivo da polícia. A adesão ao programa dava início ao "Gerenciamento dos Casos” pela equipe do CIRV, com destaque para o com encaminhamento da clientela para atividades esportivas, culturais e programas de emprego, entre outros, adequados ao perfil do jovem.

\section{A prevenção segundo os policiais escoceses: o discurso das evidências científicas}

A polissemia do termo prevenção saltou da boca dos policiais escoceses para justificar formas heterodoxas de intervenção no problema da juventude. Há o reconhecimento dos múltiplos fatores de risco que atravessam a vida dos segmentos vulneráveis da sociedade. $\mathrm{O}$ emaranhado das patologias formado pela desorganização familiar, somada ao consumo de álcool e drogas e o estilo de vida das periferias urbanas de Glasgow (deprived areas), forjariam uma espécie de tríade perversa, amplificando os riscos de envol- 
vimento com atividades criminosas e violentas. Esses "efeitos de vizinhança" ${ }^{16}$ que atribuem uma correlação determinística entre fatores comunitários e propensão social ao crime, pobreza, desescolarização, baixos indicadores de saúde vêm sendo amplamente utilizados no Reino Unido, e tem na matriz epidemiológica uma forte ligação. Esses estudos corroboram para uma prática bastante comum no fazer político Britânico, e em particular no modelo político neo-tecnocrático do Partido Nacional Escocês (que se encontrava no poder à época deste programa) e que se estrutura a partir de iniciativas respaldadas por evidências cientificas (o chamado evidence-based policy making). Este modelo está sujeito a críticas quanto aos limites epistemológicos em torno de uma falsa neutralidade cientifica e o reforço de uma doxa neoliberal cujo resultado são políticas e intervenções focadas na mudança de comportamento individual - e nas correlações entre esses comportamentos e fatores patológicos associados a vizinhança, havendo pouca ênfase nos fatores estruturais em que a ação individual se coloca ${ }^{17}$.

A prevenção baseada em evidências denota a crença nos estudos acadêmicos, notadamente do campo da epidemiologia e da saúde pública, para dar embasamento ao planejamento das intervenções, tornando-as mais eficazes em seus resultados. Tomando por base esse modelo mobiliza-se um diagnóstico-justificativa para uma intervenção precoce (early intervention) junto aos grupos atendidos. As evidências permitem capturar fragmentos iniciais do que virão a ser aqueles indivíduos se nada for feito para frear a escalada criminosa e ou violenta:

É óbvio que se você foi criado em uma área "carente" em um ambiente familiar violento, onde o seu pai bate na sua mãe, você está praticamente destinado, você está pré-programado a ser violento, a atacar.

A referência aos aportes da saúde pública confirma ainda a aposta na prevenção da violência na primeira infância, que se justifica pela ideia de evolução do anti-social behaviour (ASB). Termo "guarda-chuva" que tem sido usado como um dispositivo de criminalização das condutas juvenis, concedendo a polícia e outras autoridades locais poderes para aplicar sanções sob a alegação de que a pessoa agiu de forma a causar ou era suscetível de causar dano, alarme, ou perigo a alguém ou a um coletivo de pessoas, sendo necessária a pronta intervenção ${ }^{18}$.

$\mathrm{Na}$ experiência dos agentes escoceses, a contrapartida para "tirar os jovens do crime", sobretudo os do sexo masculino, seria também ocupar seu tempo (suas mentes) com práticas esportivas. O esporte atuaria como um instrumento que os "desviaria" do caminho das drogas, especialmente o álcool, dando um rumo as suas trajetórias cambiantes.

Incorporar as figuras de autoridade e prestígio da família nas intervenções seria uma outra via para o engajamento dos sujeitos nas terapias corretivas e atingir o sucesso. A agência dos jovens é acionada somente para colocá-los no lugar de responsáveis pelo sofrimento no qual supostamente vivem. Nessa construção, o sujeito que necessita ser objeto de intervenção é descrito como uma espécie de vítima de si mesmo e como um risco para os outros e mais especificamente para a "coletividade". A reiteração desta mensagem parece criar eficácia discursiva para a aceitação dos indivíduos, de suas famílias, e das comunidades da necessidade de intervenção e controle do Estado:

[...] eles podem não se tornar cientistas, mas pode ser que contribuam de volta para a Comunidade.

Vê-se aqui uma racionalidade atuarial que contabiliza os investimentos feitos pelos programas sociais na prevenção. Espera-se que os participantes devolvam à coletividade as dádivas recebidas no trajeto da conversão, dando provas de internalização do autocontrole das pulsões ${ }^{19}$, exibindo um novo ethos, item essencial para sua autocorreção social e moral.

\section{Discussão}

O trabalho de campo orientado pela abordagem interpretativa ${ }^{5}$ permitiu contornar os dilemas da generalização na comparação antropológica, trazendo à tona as eventuais equivalências e distinções nos estilos de controle criminal que estruturam as narrativas policiais sobre as juventudes. Tornou possível o entendimento de significados locais sobre a prevenção da violência relacionando-a aos contextos das instituições policiais, sem, no entanto, generalizar através dos casos apresentados, mas estabelecendo pontes conceituais entre eles a partir dos sentidos atribuídos pelos interlocutores às suas práticas.

Em ambos os campos, os policiais parecem se colocar como "educadores" de uma população hipossuficiente, cujos problemas acabam por demandar intervenções de caráter moral. Assumir esse papel pedagógico é se deslocar da função de agente repressivo, substituindo o combate pela compreensão das dificuldades a que estão sub- 
metidos os residentes das favelas cariocas ou das "deprived areas" de Glasgow. Porém, quando se pressupõe a visão das áreas pobres como espaço de intervenção pedagógica da polícia, essa prerrogativa pode conceder aos policiais licenças a intromissão em múltiplas esferas da vida pessoal e coletiva dos habitantes, incluindo juízos morais sobre seus comportamentos.

Tanto os policiais de Glasgow quanto seus pares no Rio de Janeiro conceberam uma apresentação de si como modelos de referência positiva para os jovens. O objetivo esperado seria a interiorização de um padrão de conduta moral ordeiro e civilizado. É preciso pensar o quanto esse olhar que se ancora em um sentido missionário ou de salvação acaba também por produzir uma surdez em relação ao outro e à sua capacidade de elaborar suas próprias narrativas. Uma implicação desse paradigma é que reproduz o não diálogo, conferindo às comunidades locais e a seus habitantes uma posição de não saber, parecendo atuar como tutores de um capital ético e moral a ser transmitido.

Observa-se também a ambição de extensão do controle para o contexto familiar dos atendidos. Tem-se que o engajamento de pais e parentes próximos é uma peça importante e complementar às medidas de prevenção. Os policiais reconhecem a potência dos vínculos próximos para o alcance das transformações pretendidas, os chamados aliciamentos preventivos. Presume-se, assim, que os bons exemplos, vindo de policiais e parentes, produzam um efeito descriminalizador. Nos dois contextos a prevenção consiste em conter a reprodução do chamado "anti-social behaviour" (ASB) ou do "envolvimento com o crime". Ambas são categorias acusatórias que autorizam a ampliação das vigilâncias difusas e controles estendidos sobre e entre os grupos, porém, com aplicações e consequências distintas.

No Brasil, a noção de "envolvido", conforme designam Cecchetto et al..$^{20}$, consiste em categoria acusatória, acionada como uma modalidade de rotulação criminal. Seu rendimento é a instrumentalização de uma criminologia persecutória do desvio e corretora da sedução pelo crime. Ela une estigma e condenação e autoriza uma série de violações e violências por quem exerce a autoridade legal e ilegal, legítima ou ilegítima. Essa classificação faz dessa juventude alvo de práticas discriminatórias e de exceção por grupos que exercem o domínio armado nos territórios como policiais, milícias e grupos de tráfico.

No contexto britânico, a agenda do ASB atrai muitos gestores sendo uma poderosa metáfora para ausência de ordem e controle. Ela corresponde à idealização da interrupção do ciclo de violência em seus estágios iniciais e na manutenção da ordem através do policiamento de pequenas incivilidades e outros sinais sutis de crime. Clama pela responsabilidade social mais que direitos individuais, privilegiando o comportamento moral adequado e aceitável. Essa lógica tem sido um fator-chave para o afastamento de uma abordagem de bem-estar social para uma abordagem mais punitiva, erodindo as proteções sociais dadas as populações vulneráveis ${ }^{13}$.

A ênfase em atividades esportivas esteve presente em ambos os cenários. Com relação a isto, vemos ainda em Monteiro ${ }^{21}$ que o objetivo dessas atividades estaria aquém da profissionalização. Sabe-se que as chances são reduzidas e poucos de fato conseguem destaque e sucesso nestas carreiras. O intuito da prática esportiva então, seria fazê-los compreender sua eficácia simbólica: saber perder, saber competir com base nas mesmas regras para todos os jogadores, aprender a conduzir-se na vida com disciplina $a^{21}$ ( $\left.\mathrm{p} .179\right)$.

Os caminhos para o des-envolvimento, portanto, implicariam em reconhecer a condição de vulnerável ou em risco e aceitar de forma resignada e de bom grado o que lhe for ofertado como alternativa para quaisquer que sejam os motivos que os levaram a serem vistos como alguém em situação de "envolvido" com o crime ou com um comportamento antissocial. Os sujeitos seriam os únicos responsáveis pela situação na qual se encontram. No entanto, sua agência é limitada pelas normas impostas pelos agentes, conferindo-lhes um papel passivo diante do que lhes foi planejado. Para os que se recusam a "jogar" existe sempre a ameaça do policiamento repressivo e de uso da violência, recursos que correspondem à natureza do trabalho policial, caracterizado pelo uso autorizado da força concreta ou potencialmente, sob o império da lei, para produzir obediências visando a paz social ${ }^{21}$.

Cabe ressaltar que as intervenções em geral são pensadas e formuladas para o público masculino. Como consequência as mulheres aparecem nessas narrativas como coadjuvantes, evidenciando uma dificuldade aparentemente não percebida de lidar com as questões relacionadas à vulnerabilidade feminina. Apesar das ações promovidas focalizarem homens, nenhuma menção foi feita às relações de gênero ou a construção social das masculinidades nos contextos locais. São ainda poucas as intervenções que utilizam as lentes do gênero para pautar suas ações com as juventudes. Ignoram-se que as interações confli- 
tuosas entre policiais e jovens moradores dessas áreas são atravessadas por valores machistas que dominam ambos os grupos de homens, conduzindo-os a uma relação baseada na desconfiança mútua e falta de reciprocidade ${ }^{22}$.

Nos dois contextos a ideia de prevenção adquire um tom prescritivo que traz consigo um veredito antecipatório: "cortar o mal pela raiz". Antes e para além do fato ter ocorrido ou da ofensa ter sido cometida, o projeto regulatório atua em nome da interrupção da trajetória desviante. Evidencia-se a preocupação com o que pode acontecer no futuro, autorizando a intensificação da vigilância das autoridades. Uma visão visceralmente agarrada a uma concepção de profecia que se cumpre, marcando sujeitos como alguém que potencialmente virá a se envolver em uma atividade criminosa, produzindo-os como tal. Revela-se o uso político dessas previsões sobre o futuro através da manipulação do presente de sujeitos categorizados como ameaça ou risco.

Ideias sobre "comportamento de risco" correspondem a uma concepção patologizante sobre o universo juvenil das periferias pobres como um emaranhado de patologias que deram corpo a noção de "underclass" 23. Uma representação que naturaliza os mecanismos de (re) produção das desigualdades e da mobilidade social. Essa ideologia reproduz uma lógica perversa, politicamente rentável, contra os sujeitos que moram em localidades socialmente desfavorecidas como a de que tendem a sofrer de toda uma série de problemas, incluindo desorganização familiar e que seriam mais propensos a criminalidade ${ }^{24}$. O peso parece incidir sobre o ambiente desestruturado, imagem utilizada para descrever um segmento que não é apenas "economicamente privado", mas que manifesta um conjunto de valores, atitudes, crenças, normas e comportamentos distintos de um padrão considerado ideal.

\section{Conclusão}

Buscou-se neste texto explorar as narrativas de policiais sobre projetos ou ações de prevenção da violência cujos destinatários seriam parcelas da juventude caracterizadas como vulneráveis ou expostas às diversas manifestações das violências e ao crime. Refletiu-se sobre as manobras e mecanismos que moldam as formas de controle, vigilância e punição das juventudes em contextos distintos, procurando estabelecer pontes teóricas e conceituais entre realidades socio-geográficas diferentes, mas que compartilham de certas premissas sobre a criminalidade juvenil.

Explorou-se temas convergentes no que se refere as ações sociopolíticas de culpabilização e criminalização que fraturam os grupos entre os "cidadãos de bem" e os "criminosos", entre os merecedores das tutelas pedagógicas e os "perdidos". Ao focalizar os programas de prevenção a partir das lentes de seus operadores policiais, buscou-se desvelar as lógicas com as quais operam os agentes na interação com o público-alvo das intervenções, marcadamente os homens jovens, dos meios populares. Os dados empíricos possibilitaram traçar paralelos entre crenças dominantes, axiomas e dogmas sobre a assim chamada juventude de risco, indo além de exceções e variantes de um lado e de outro. Ao se examinar as tramas de relações sociais e simbólicas que se tecem quando se fala de intervenções baseadas em evidências, verificou-se o recurso às abordagens mais ou menos inclusivas, mais ou menos patologizantes, que se apoiam em generalizações, ignorando a variação entre as pessoas e dentro das pessoas.

A opção por realizar um estudo sobre a prevenção da violência e inseri-lo em uma reflexão mais geral sobre os elementos políticos e morais em jogo em dois contextos distintos foi impulsionada justamente pelo quadro alarmante de homicídios de jovens negros e das periferias no Brasil. Levar a sério a questão da mortalidade juvenil no país, dando sua dimensão como um problema de saúde pública é desvelar a realidade indizível das disparidades no dispositivo punitivo entre as sociedades. Descortina como o esvaziamento das discussões sobre prevenção e de políticas sociais para juventudes deu lugar a morte e a violência, desigualmente distribuídas e evitáveis. As diferenças indicam mais do que variações contextuais ou o modus operandis das políticas de segurança dos países, sugerem ethos distintos e, indo além, contrastantes concepções de justiça e democracia.

Desse modo tornam-se ainda mais importantes os estudos críticos que localizem essa agenda em um debate global sobre as formas de controle do Estado e de reprodução das violências e os impactos sobre a saúde das juventudes moradoras de áreas periféricas ao redor do mundo. 


\section{Colaboradores}

JS Corrêa, FR Cecchetto e FL Fernandes participaram da concepção e redação de todo o argumento do texto.

\section{Referências}

1. World Health Organization (WHO). Preventing of Youth Violence an overview of evidence. Genebra: WHO; 2015.

2. Dahlberg LL, Krug EG. Violência: um problema global de saúde pública. Cien Saud Colet 2006; 11(Supl.):1163-1178.

3. Atienzo EE, Baxter SK, Kaltenthaler E. Intervenções para prevenir a violência juvenil na América Latina: uma revisão sistemática. Int J Saude Publica 2017; 62(1):15-29.

4. Lemgruber J, Boiteux L. O fracasso da guerra às drogas. In: Lima RS, De Ratton JL, Azevedo RG, organizadores. Crime, polícia e justiça no Brasil. São Paulo: Editora Contexto; 2014. p. 357-362.

5. Corrêa JS. As percepções de gestores de programas sociais $e$ de policiamento sobre juventudes, vulnerabilidades e prevenção da violência: diálogos entre Rio de Janeiro (Brasil) e Glasgow (Escócia) [tese]. Rio de Janeiro: Escola Nacional de Saúde Pública Sergio Arouca; 2018.

6. Silvestri M. Gender diversity: two steps forward, one step back. Policing 2015; 9(1):56-64.

7. Muniz J. Ser policial é, sobretudo, uma razão de ser: cultura e cotidiano da Polícia Militar do Estado do Rio de Janeiro [tese]. Rio de Janeiro: IUPERJ; 1999.

8. Geertz C. A interpretação das culturas. Rio de Janeiro: Zahar; 1989.

9. Minayo MCS. O desafio do conhecimento: pesquisa qualitativa em saúde. São Paulo, Rio de Janeiro: $\mathrm{Hu}-$ citec; 2010.

10. Brasil. Secretaria de Estado de Segurança do Estado do Rio de Janeiro (SESEG). Unidade de Polícia Pacificadora - UPP: da origem do programa à política de pacificação. Rio de Janeiro: SESEG; 2015.

11. Muniz J, Mello K. Nem Tão Perto, Nem Tão Longe: O dilema da construção da autoridade policial nas UPP. Civitas 2015; 15(1):44-65.

12. Fernandes FL. Youth Gang Members in Rio de Janeiro: The Face of a 'Lost Generation' in an Age of Fear and Mistrust. Bull Lat Am Stud 2013; 32(2):210-223.

13. Rodrigues A, Siqueira R. As Unidades de Polícia Pacificadora e a segurança pública no Rio de Janeiro. In: Rodrigues A, Siqueira R, Lissovsky M. Unidades de Polícia Pacificadora: debates e reflexões. Rio de Janeiro: ISER; 2012. p. 9-52.

14. Graham W. Global Concepts, Local Contexts - A case study of international criminal justice policy transfer in violence reduction [tese]. Glasgow: Glasgow Caledonian University; 2016.

15. Scottish Violence Reduction Unit. Glasgow's Community Initiative to Reduce Violence 1 Year Report. Glasgow; 2009.

16. Van Ham M, Manley D, Bailey N, Simpson L, Maclennan D. Neighbourhood Effects Research: New Perspectives. Berlim: Springer; 2012.

17. Fernandes FL, Swinney A, McMillan S, MacLeay D, McGhee J, Graham W, Roberts G. Rehabilitation doxa and practitioner judgment. An analysis of symbolic violence on health care provision in the Scottish prison system. Cien Saude Colet 2018; 23(9):2869-2877.

18. Crawford A. Governing Through Anti-Social Behaviour - Regulatory Challenges to Criminal Justice. $\mathrm{Br} \mathrm{J}$ Criminology 2009; 49(6):810-831. 
19. Elias N. O processo civilizador. Rio de Janeiro: Jorge Zahar; 1993.

20. Cecchetto F, Muniz J, Monteiro R. "Basta estar do lado": A construção social do envolvido-com o crime. CRH 2018; 31(82):99-116.

21. Monteiro R. Socio-Sporting Projects, Violence Prevention and Suburban Youth in the City of Rio de Janeiro. Vibrant 2011; 7(2):166-193.

22. Deuchar R. 'It's Just Pure Harassment. As If It's a Crime to Walk in the Street': Anti-social Behaviour, Youth Justice and Citizenship - The Reality for Young Men in the East End of Glasgow. Youth Justice 2010; 10(3):258-274

23. Morris M. From the culture of poverty to the underclass: An analysis of a shift in public language. $\mathrm{Am} \mathrm{So-}$ ciol 1989; 20(2):123-133.

24. Wacquant LJ. Os condenados da cidade: estudos sobre marginalidade avançada. Goiânia: Sociedade e Cultura; 2001.

Artigo apresentado em 20/11/2020

Aprovado em 25/05/2021

Versão final apresentada em 27/05/2021

Editores-chefes: Romeu Gomes, Antônio Augusto Moura da Silva 